\title{
Cytogenetic evaluation of cataract patients occupationally exposed to ionizing radiation in northeast China
}

\author{
D.D. Zhou' ${ }^{1}$ L. Yao ${ }^{2}$, K.M. Guo ${ }^{3}$ and C.W. Lu ${ }^{4}$ \\ ${ }^{1}$ Department of Radiology, First Hospital of Jilin University, Changchun, \\ Jilin Province, China \\ ${ }^{2}$ Department of Dermatology, the First Hospital of Jilin University, Changchun, \\ Jilin Province, China \\ ${ }^{3}$ Department of Andrology, First Hospital of Jilin University, Changchun, \\ Jilin Province, China \\ ${ }^{4}$ Department of Ophthalmology, First Hospital of Jilin University, Changchun, \\ Jilin Province, China \\ Corresponding author: C.W. Lu \\ E-mail: lucwjlu@126.com \\ Genet. Mol. Res. 15 (3): gmr.15038687 \\ Received April 1, 2016 \\ Accepted May 2, 2016 \\ Published September 16, 2016 \\ DOI http://dx.doi.org/10.4238/gmr.15038687
}

Copyright $(2016$ The Authors. This is an open-access article distributed under the terms of the Creative Commons Attribution ShareAlike (CC BY-SA) 4.0 License.

ABSTRACT. Long-term radiation exposure is hazardous to health;
late-onset effects of exposure to ionizing radiation (IR) pose risks to the
lens, and are associated with other non-cancerous diseases. Individuals
occupationally exposed to low-dose IR are prone to developing eye
cataracts. Cytogenetic evaluations suggest that IR is associated with
chromosomal aberrations in occupationally exposed individuals.
However, data regarding the association between chromosomal
aberrations in cataract patients and occupational exposure to IR is
scarce. Therefore, we aimed to report the characteristics of chromosomal 
aberrations in cataract patients from a Chinese population, occupationally exposed to IR. We found that the average age and frequency of numerical chromosomal aberrations were significantly lower in the exposed patients as compared with that in the non-exposed patients. In addition, the frequencies of dicentric and acentric chromosomes were significantly higher in the exposed patients as compared with those in the non-exposed patients. Therefore, chronic occupational exposure to IR affects cataract development in the Chinese population. The age of cataract patients exposed to IR was significantly lower than the age of cataract onset in normal individuals. Based on this study, we suggest that there is an urgent need for improved radiation safety and eye protection in individuals exposed to IR in the work place.

Key words: Chromosome aberrations; Cataract; Ionizing radiation; Occupational exposure

\section{INTRODUCTION}

Long-term radiation exposure can have negative impacts on health, and late-onset health effects of ionizing radiation (IR) have been identified by long-term, large-scale epidemiological studies (Kamiya et al., 2015; Zhou et al., 2016). IR has long been known to raise the risks of cancer (Abbott, 2015). In addition, low-dose IR may increase the risk of lens opacity as well as some other non-cancerous diseases (Tucker, 2008; Hammer et al., 2013; Vano et al., 2013; Kamiya et al., 2015; Kreuzer et al., 2015). Studies have shown that individuals occupationally exposed to low-dose IR are susceptible to heart diseases and eye cataracts (Wakeford, 2009). Various factors affect cataract susceptibility, such as age and radiation (Shore et al., 2010; Wang et al., 2015). Epidemiological studies have provided further evidence regarding the potential risk of low doses of radiation on cataracts (Jacob et al., 2010). For example, there are greater incidences of radiation-associated lens changes in interventional cardiology workers, radiologists, and radiologic technologists (Chodick et al., 2008; Milacic, 2009a; Vano et al., 2010; Jacob et al., 2013).

Cytogenetic evaluations suggest that an environmental agent is responsible for altering chromosomal aberrations in individuals with occupational exposure (do Amaral et al., 2015). IR is a classic mutagen capable of inducing unstable chromosomal aberrations (Saberi et al., 2013). This was demonstrated by higher incidences of chromosomal alterations in exposed workers as compared to those in controls (Cardoso et al., 2001; Chen et al., 2014; Han et al., 2014). In the present study, we report on the association between chromosomal aberrations in cataract patients and occupational exposure to IR in the Chinese population.

\section{MATERIAL AND METHODS}

\section{Patients}

The subjects were recruited among cataract patients who sought diagnosis and treatment in the ophthalmology outpatient's clinic of the First Hospital of Jilin University. Between January 2013 and December 2015, karyotyping was carried out in 127 cataract

Genetics and Molecular Research 15 (3): gmr.15038687 
patients. This was a single-center study, and assessments of occupational exposure to ionizing radiation were carried out in the form of questionnaires. The study protocol was approved by the Ethics Committee of the First Hospital of Jilin University, Changchun, China. Written informed consents were obtained from all participants prior to enrolment into the study.

\section{Questionnaire}

An elaborate questionnaire on the patients' occupation, working conditions, age, education level, smoking history, and past medical history was given to each patient. Patients occupationally exposed to IR, including radiologic technologist, radiologist, and interventional cardiologist, were asked to provide the years of IR exposure.

\section{Cytogenetic analysis}

G-banding of metaphase chromosomes and karyotype analysis were performed according to published methods (Zhang et al., 2015). Peripheral blood samples $(0.5 \mathrm{~mL})$ from all patients were collected into sterile tubes containing $30 \mathrm{U} / \mathrm{mL}$ heparin. After a $72-\mathrm{h}$ incubation period, lymphocytes were cultured in solution (Yishengjun, Guangzhou Baidi Biotech, Guangzhou, China), and were treated with $20 \mu \mathrm{g} / \mathrm{mL}$ colcemid for $1 \mathrm{~h}$. For each individual, 200 metaphases were analyzed per slide. Dicentric, tricentric, structural, and numerical abnormal chromosomes were counted.

\section{Statistical analysis}

All data were analyzed using the SPSS v.17.0 software for Windows (SPSS, Inc, Chicago, IL, USA). Parametric variables were compared via the independent Student $t$-tests or $\chi^{2}$ tests. All results are reported as means $\pm \mathrm{SD}$ or percentages. $\mathrm{P}<0.05$ was considered to be statistically significant.

\section{RESULTS}

Of the 127 cataract patients in this study, 52 patients were occupationally exposed to IR, and 75 patients were not. The occupationally exposed patients all worked in various hospitals with diagnostic or therapeutic radiation facilities. Of the 52 exposed patients ( 28 men and 24 women), those that operated IR-associated instruments for more than five years were considered to be chronically exposed to low-dose radiation. The average age of these patients was $50.27 \pm 5.64$ years, and the average years of IR exposure in those individuals were 9.29 \pm 2.84 years. Of the 75 non-exposed subjects ( 41 men and 34 women), the average age was $59.69 \pm 4.90$ years. Results suggested that the occupationally exposed cataract patients were younger than the non-exposed cataract patients $(\mathrm{P}<0.001)$.

Results indicated that the number of patients with abnormal karyotype was significantly higher in the exposed patients as compared with that in the non-exposed patients $(\mathrm{P}<0.001)$ (Table 1). Total chromosomal numbers detected in abnormal karyotypes are shown in Table 2. Total chromosomal abnormalities were found in 92 and 47 cells of all exposed and non-exposed patients, respectively. In addition, dicentric and acentric chromosomes were significantly higher in the exposed patients as compared with those in the non-exposed patients 
$(\mathrm{P}<0.01)$. Frequency of numerical abnormal karyotypes was found to be significantly lower in the exposed patients as compared with that in the non-exposed patients $(\mathrm{P}<0.001)$. There was no statistical difference in structural abnormal karyotypes between the exposed and nonexposed men $(\mathrm{P}>0.05)$. To determine the degrees of chromosomal aberrations, 200 metaphases were analyzed per patient. Frequency of chromosomal aberration was significantly higher in the exposed patients as compared with that in the non-exposed patients $(\mathrm{P}<0.001)$ (Table 3$)$.

Table 1. Number of cataract patients with abnormal karyotype.

\begin{tabular}{l|c|c|c}
\hline & Non-exposed group (75) & Exposed group (52) & $\mathrm{P}$ value $^{\mathrm{a}}$ \\
\hline No. of patients & $36(48 \%)$ & $44(84.6 \%)$ & $0.000^{*}$ \\
\hline
\end{tabular}

Data are reported as $\mathrm{N}(\%) ;{ }^{\mathrm{a}} \chi^{2}$-test; $* \mathrm{P}<0.001$ compared with non-exposed group.

Table 2. Chromosomal abnormalities in cataract patients.

\begin{tabular}{l|c|c|c}
\hline & Non-exposed group (75) & Exposed group (52) & P value $^{\mathrm{a}}$ \\
\hline Total & 92 & 47 & $0.002^{*}$ \\
\hline Dicentrics & $6(12.77 \%)$ & $36(39.13 \%)$ & $0.002^{*}$ \\
\hline Acentrics & $4(8.51 \%)$ & $30(32.61 \%)$ & 0.152 \\
\hline Structural abnormal// & $16(34.04)$ & $20(21.74)$ & $0.000^{* *}$ \\
\hline Numeral abnormal & $21(44.68 \%)$ & $6(6.52 \%)$ & \\
\hline
\end{tabular}

Data are reported as $\mathrm{N}(\%) ;{ }^{\mathrm{a}} \chi^{2}$-test, ${ }^{*} \mathrm{P}<0.01 ;{ }^{*} \mathrm{P}<0.001$ compared with non-exposed group.

Table 3. Frequencies of chromosomal aberrations in exposed and non-exposed groups.

\begin{tabular}{l|c|c|c}
\hline & Non-exposed group (75) & Exposed group (52) & P value $^{\mathrm{a}}$ \\
\hline ChA/200 cells & $0.63 \pm 0.51$ & $1.77 \pm 0.92$ & $0.000^{*}$ \\
\hline
\end{tabular}

ChA: chromosomal aberration; data are reported as means $\pm \mathrm{SD}$, aStudent's $t$-test; $* \mathrm{P}<0.001$ compared with nonexposed group.

\section{DISCUSSION}

The health risks arising from exposure to low doses of IR have been identified in previous studies (Kamiya et al., 2015), and should be re-evaluated (El-Saghire et al., 2013). The incidences of cataracts are closely associated with IR exposure (Shore et al., 2010; Kleiman, 2012). Milacic (2009a) reported that occupational exposure to low doses of IR is a significant factor for cataract development. Epidemiological studies have provided clear evidence regarding the potential risks of radiation-associated lens changes in the eyes of workers occupationally exposed to IR (Jacob et al., 2010; Vano et al., 2010; Ciraj-Bjelac et al., 2012). It is known that accommodative capability of the eye depends on an individual's age, the absorbed dose, and duration of IR exposure (Sergienko and Fedirko, 2002); in individuals exposed to various doses of IR, it was found to be reduced in younger patients. However, Auvinen et al. (2015) reported that the frequency of lens opacities did not increase in physicians with occupational exposure to IR. Therefore, we studied chromosomal aberrations in cataract patients from a Chinese population occupationally exposed to IR. We found that the average age of exposed patients was significantly lower than that of non-exposed patients.

Cytogenetic studies have demonstrated that low levels of chronic radiation exposure can potentially increase the frequency of chromosomal aberrations and aneuploidy in somatic cells (Kasuba et al., 2008). Ciraj-Bjelac et al. (2012) reported radiation-associated posterior 
lens changes in the eyes of interventional cardiology staff. However, despite these study results, risk factors to the eyes are often overlooked. Until recently, IR was considered a deterministic factor for cataract development (Hammer et al., 2013). As a result, mechanical shielding from these radiations was recommended in order to minimize the development of radiation-induced cataracts (Lipman et al., 1988). However, one study reported that the frequency of lens opacities did not increase in physicians with occupational exposure to IR (Auvinen et al., 2015). In this study, we detected greater abnormal karyotypes in IR exposed patients than in non-exposed patients. The frequencies of dicentric and acentric chromosomes were also significantly higher in the exposed patients as compared with those in the nonexposed patients. Numerical chromosome abnormality was significantly lower in the exposed patients as compared with that in the non-exposed patients. These results were consistent with previous studies (Jha and Sharma, 1991; Cardoso et al., 2001; Santovito et al., 2014).

Chronic long-term exposure to low doses of IR could increase chromosomal aberrations in hospital workers (Santovito et al., 2014). The cumulative effects of low-level chronic IR exposure are higher for those occupationally exposed to IR (Saberi et al., 2013). Similar to previous studies (Barquinero et al., 1993; Kasuba et al., 2008; Milacic, 2009b; Han et al., 2014), we found that chromosomal aberrations were significantly elevated in the exposed patients as compared with that in the non-exposed patients.

In summary, chronic long-term occupational exposure to IR affects cataract development in the Chinese population. The age of cataract onset in patients occupationally exposed to IR was significantly lower than that of non-exposed individuals. The elevated number of chromosomal aberrations in individuals exposed to IR suggests that there is an urgent need for improved radiation safety and eye protection.

\section{Conflicts of interest}

The authors declare no conflict of interest.

\section{ACKNOWLEDGMENTS}

We would like to express our sincere gratitude to all the staff of the genetics laboratory, First Hospital of Jilin University for their excellent work.

\section{REFERENCES}

Abbott A (2015). Researchers pin down risks of low-dose radiation. Nature 523: 17-18. http://dx.doi.org/10.1038/523017a Auvinen A, Kivelä T, Heinävaara S and Mrena S (2015). Eye lens opacities among physicians occupationally exposed to ionizing radiation. Ann. Occup. Hyg. 59: 945-948. http://dx.doi.org/10.1093/annhyg/mev022

Barquinero JF, Barrios L, Caballín MR, Miró R, et al. (1993). Cytogenetic analysis of lymphocytes from hospital workers occupationally exposed to low levels of ionizing radiation. Mutat. Res. 286: 275-279. http://dx.doi.org/10.1016/0027$\underline{5107(93) 90192-\mathrm{I}}$

Cardoso RS, Takahashi-Hyodo S, Peitl P Jr, Ghilardi-Neto T, et al. (2001). Evaluation of chromosomal aberrations, micronuclei, and sister chromatid exchanges in hospital workers chronically exposed to ionizing radiation. Teratog. Carcinog. Mutagen. 21: 431-439. http://dx.doi.org/10.1002/tcm.1030

Chen Y, Zhou PK, Zhang XQ, Wang ZD, et al. (2014). Cytogenetic studies for a group of people living in Japan 1 year after the Fukushima nuclear accident. Radiat. Prot. Dosim. 159: 20-25.http://dx.doi.org/10.1093/rpd/ncu180

Chodick G, Bekiroglu N, Hauptmann M, Alexander BH, et al. (2008). Risk of cataract after exposure to low doses of ionizing radiation: a 20-year prospective cohort study among US radiologic technologists. Am. J. Epidemiol. 168: 620-631.http://dx.doi.org/10.1093/aje/kwn171

Genetics and Molecular Research 15 (3): gmr.15038687 
Ciraj-Bjelac O, Rehani M, Minamoto A, Sim KH, et al. (2012). Radiation-induced eye lens changes and risk for cataract in interventional cardiology. Cardiology 123: 168-171. http://dx.doi.org/10.1159/000342458

do Amaral FP, do Amaral EJ, do Amaral MP, Lopes LS, et al. (2015). Cytogenetic evaluation of tannery workers in the city of Teresina, northeastern Brazil. Genet. Mol. Res. 14: 18799-18807.http://dx.doi.org/10.4238/2015.December.28.29

El-Saghire H, Michaux A, Thierens H and Baatout S (2013). Low doses of ionizing radiation induce immune-stimulatory responses in isolated human primary monocytes. Int. J. Mol. Med. 32: 1407-1414.

Hammer GP, Scheidemann-Wesp U, Samkange-Zeeb F, Wicke H, et al. (2013). Occupational exposure to low doses of ionizing radiation and cataract development: a systematic literature review and perspectives on future studies. Radiat. Environ. Biophys. 52: 303-319. http://dx.doi.org/10.1007/s00411-013-0477-6

Han L, Zhao FL, Sun QF, Wang P, et al. (2014). Cytogenetic analysis of peripheral blood lymphocytes, many years after exposure of workers to low-dose ionizing radiation. Mutat. Res. Genet. Toxicol. Environ. Mutagen. 771: 1-5. http:// dx.doi.org/10.1016/j.mrgentox.2014.06.003

Jacob S, Michel M, Spaulding C, Boveda S, et al. (2010). Occupational cataracts and lens opacities in interventional cardiology (O'CLOC study): are X-Rays involved? Radiation-induced cataracts and lens opacities. BMC Public Health 10: 537. http://dx.doi.org/10.1186/1471-2458-10-537

Jacob S, Boveda S, Bar O, Brézin A, et al. (2013). Interventional cardiologists and risk of radiation-induced cataract: results of a French multicenter observational study. Int. J. Cardiol. 167: 1843-1847. http://dx.doi.org/10.1016/j. ijcard.2012.04.124

Jha AN and Sharma T (1991). Enhanced frequency of chromosome aberrations in workers occupationally exposed to diagnostic X-rays. Mutat. Res. 260: 343-348. http://dx.doi.org/10.1016/0165-1218(91)90020-M

Kamiya K, Ozasa K, Akiba S, Niwa O, et al. (2015). Long-term effects of radiation exposure on health. Lancet 386: 469478. http://dx.doi.org/10.1016/S0140-6736(15)61167-9

Kasuba V, Rozgaj R and Jazbec A (2008). Chromosome aberrations in peripheral blood lymphocytes of Croatian hospital staff occupationally exposed to low levels of ionising radiation. Arh. Hig. Rada Toksikol. 59: 251-259. http://dx.doi. org $/ 10.2478 / 10004-1254-59-2008-1909$

Kleiman NJ (2012). Radiation cataract. Ann. ICRP 41: 80-97. http://dx.doi.org/10.1016/j.icrp.2012.06.018

Kreuzer M, Auvinen A, Cardis E, Hall J, et al. (2015). Low-dose ionizing radiation and cardiovascular diseases strategies for molecular epidemiological studies in Europe. Mutat. Res. Rev. Mutat. Res. 764: 90-100. http://dx.doi. org/10.1016/j.mrrev.2015.03.002

Lipman RM, Tripathi BJ and Tripathi RC (1988). Cataracts induced by microwave and ionizing radiation. Surv. Ophthalmol. 33: 200-210. http://dx.doi.org/10.1016/0039-6257(88)90088-4

Milacic S (2009a). Risk of occupational radiation-induced cataract in medical workers. Med. Lav. 100: 178-186.

Milacic S (2009b). Chromosomal aberrations after exposure to low doses of ionizing radiation. J. BUON 14: 641-646.

Saberi A, Salari E and Latifi SM (2013). Cytogenetic analysis in lymphocytes from radiation workers exposed to low level of ionizing radiation in radiotherapy, CT-scan and angiocardiography units. Mutat. Res. 750: 92-95. http://dx.doi. org/10.1016/j.mrgentox.2012.10.001

Santovito A, Cervella P and Delpero M (2014). Increased frequency of chromosomal aberrations and sister chromatid exchanges in peripheral lymphocytes of radiology technicians chronically exposed to low levels of ionizing radiations. Environ. Toxicol. Pharmacol. 37: 396-403.http://dx.doi.org/10.1016/j.etap.2013.12.009

Sergienko NM and Fedirko P (2002). Accommodative function of eyes in persons exposed to ionizing radiation. Ophthalmic Res. 34: 192-194.http://dx.doi.org/10.1159/000063879

Shore RE, Neriishi K and Nakashima E (2010). Epidemiological studies of cataract risk at low to moderate radiation doses: (not) seeing is believing. Radiat. Res. 174: 889-894. http://dx.doi.org/10.1667/RR1884.1

Tucker JD (2008). Low-dose ionizing radiation and chromosome translocations: a review of the major considerations for human biological dosimetry. Mutat. Res. 659: 211-220. http://dx.doi.org/10.1016/j.mrrev.2008.04.001

Vano E, Kleiman NJ, Duran A, Rehani MM, et al. (2010). Radiation cataract risk in interventional cardiology personnel. Radiat. Res. 174: 490-495. http://dx.doi.org/10.1667/RR2207.1

Vano E, Kleiman NJ, Duran A, Romano-Miller M, et al. (2013). Radiation-associated lens opacities in catheterization personnel: results of a survey and direct assessments. J. Vasc. Interv. Radiol. 24: 197-204.http://dx.doi.org/10.1016/j. jvir.2012.10.016

Wakeford R (2009). Radiation in the workplace-a review of studies of the risks of occupational exposure to ionising radiation. J. Radiol. Prot. 29: A61-79. http://dx.doi.org/10.1088/0952-4746/29/2A/S05

Wang X, Sun J, Dang GF, Gao Y, et al. (2015). Antioxidant content and cytological examination of aqueous fluid from patients with age-related cataracts at different stages. Genet. Mol. Res. 14: 6251-6255. http://dx.doi.org/10.4238/2015.June.9.11

Zhang HG, Liu XY, Hou Y, Chen S, et al. (2015). Reproductive outcome of a case with familial balanced translocation t (3;6): implications for genetic counseling. Genet. Mol. Res. 14: 2809-2815. http://dx.doi.org/10.4238/2015. March.31.11

Zhou DD, Hao JL, Guo KM, Lu CW, et al. (2016). Sperm quality and DNA damage in men from Jilin Province, China, who are occupationally exposed to ionizing radiation. Genet. Mol. Res. 15: gmr.15018078.

Genetics and Molecular Research 15 (3): gmr.15038687 